\title{
Penentuan Prioritas Risiko pada Rancangan Rantai Pasok Biodiesel dari Minyak Goreng Bekas di Kota Padang
}

\author{
Ruri Kurnia ${ }^{1}$, Rika Ampuh Hadiguna ${ }^{2 *}$ \\ $1 *, 2)$ Jurusan Teknik Industri, Fakultas Teknik, Universitas Andalas, \\ email : rurikurnia@yahoo.com, hadigunaeft.unand.ac.id
}

\begin{abstract}
Abstrak
A design of biodiesel supply chain from waste cooking oil conducted in previous studies. Implementation of supply chain design needs to be studied more in depth and comprehensive. One aspect of the study is a supply chain risk management. Supply chain risk management is important because many events in supply chain which raises operational problems and the cessation of business activity. Because of vulnerability of the supply chain to various internal and external risks, the study of risk sources is needed. This study examines the sources of risk and the weighting that may occur along the supply chain for the distribution of biodiesel from waste cooking oil from suppliers that located in various places until the sale of biodiesel to consumers that are targeted to the public in Padang. The method used in this research is fuzzy AHP with triangular fuzzy number approach. Risk identification is done with the study of literature and assessment by experts. Based on the results obtained sequences risks from largest to smallest weight are raw materials, market, quality, production, transportation, and partnerships.
\end{abstract}

Keywords: Risk, Weighting, Supply Chain, Biodiesel, Fuzzy AHP

\begin{abstract}
Abstrak
Sebuah rancangan rantai pasok biodiesel dari minyak goreng bekas telah dihasilkan pada penelitian sebelumnya. Penerapan rancangan rantai pasok kini perlu dikaji lebih mendalam dan komprehensif. Salah satu aspek kajian tersebut adalah manajemen risiko rantai pasok. Kajian risiko rantai pasok penting karena banyak kejadian dalam rantai pasok yang menimbulkan permasalahan operasional dan terhentinya aktivitas bisnis. Karena kerentanan rantai pasok terhadap berbagai risiko internal dan eksternal, maka kajian terhadap sumber-sumber risiko sangat diperlukan. Penelitian ini mengkaji sumber-sumber risiko dan pembobotannya yang mungkin terjadi di sepanjang rantai pasok biodiesel untuk pendistribusian minyak goreng bekas dari supplier yang berada di berbagai tempat hingga penjualan biodiesel ke konsumen yang ditargetkan untuk masyarakat se-Kota Padang. Metoda yang digunakan dalam penelitian ini yaitu fuzzy AHP dengan pendekatan triangular fuzzy number. Identifikasi risiko dilakukan dengan studi literatur dan penilaian oleh pakar. Berdasarkan hasil penelitian diperoleh urutan risiko dari bobot terbesar hingga terkecil yaitu risiko bahan baku, pasar, mutu, produksi, transportasi, dan kemitraan.
\end{abstract}

Kata kunci : Risiko, Pembobotan, Rantai Pasok, Biodiesel, Fuzzy AHP

\section{Pendahuluan}

Salah satu faktor yang memegang peranan penting akan perkembangan sebuah perusahaan adalah faktor sumber daya manusia. Sumber daya manusia merupakan aset yang perlu diperhatikan bagi perusahaan, sehingga perusahaan

*Korespondensi Penulis perlu mendorong sumber daya manusia yang ada agar dapat mengembangkan kemampuan serta keterampilan yang dimiliki secara optimal. Salah satu upaya yang dapat dilakukan perusahaan adalah dengan memberikan kompensasi yang adil dan sesuai dengan beban jabatan yang dipegang (Sukwadi, 2014).

Menurut Wijaya (2011) biodiesel merupakan 
bahan bakar nabati pengganti solar yang digunakan untuk menggerakkan mesin diesel. Biodiesel dihasilkan dari minyak tumbuhan nabati atau minyak hewan melalui reaksi fisika dan kimia dengan cara direaksikan dengan methanol pada proses transesterifikasi sehingga diperoleh minyak methil ester (ME). Salah satu kelebihan biodiesel dibandingkan dengan solar yaitu bersifat ramah lingkungan karena menghasilkan emisi yang jauh lebih rendah.

Kota Padang sebagai ibukota provinsi Sumatera Barat memiliki potensi menghasilkan minyak goreng bekas yang cukup besar. Minyak goreng sebagai bahan utama penggorengan dibutuhkan oleh semua kalangan masyarakat yang pada akhirnya akan menghasilkan minyak goreng bekas. Menurut Hadiguna dan $\mathrm{Pu}-$ tra (2015) penduduk Kota Padang yang tersebar dalam 11 kecamatan dan 104 kelurahan memiliki potensi yang besar untuk melakukan pengembangan biodiesel yang berasal dari minyak goreng bekas. Selain memiliki jumlah penduduk yang besar Kota Padang juga merupakan kota pariwisata yang memiliki beragam fasilitas seperti rumah makan, restoran, hotel, dan fastfood yang juga menghasilkan minyak goreng bekas setiap harinya. Berdasarkan data olahan hasil observasi diperkirakan $8326,67 \mathrm{~kg}$ minyak goreng bekas dihasilkan dalam satu hari di Kota Padang.

Hasil rancangan rantai pasok biodiesel di Kota Padang ditunjukkan pada Gambar 1.

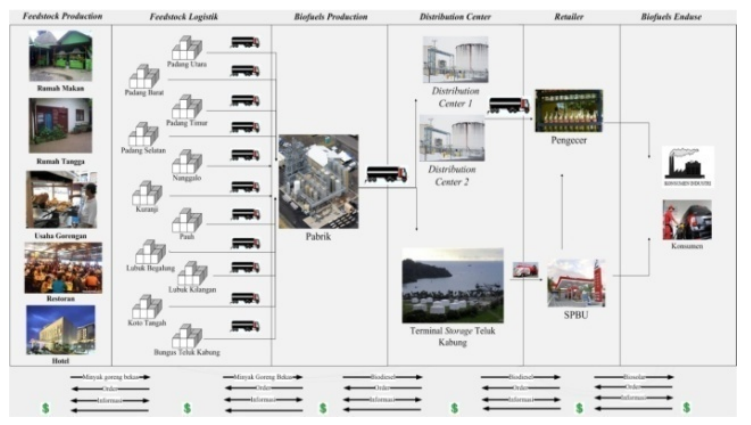

Gambar 1: Model jaringan rantai pasok biodiesel di kota Padang (Hadiguna dan Putra, 2015)

Banyak kejadian yang terjadi dalam rantai pasok yang menyebabkan permasalahan operasional dan terhentinya aktivitas bisnis. Sejumlah hubungan perlu dibuat antara anggota rantai pasok untuk mengurangi kemungkinan risiko yang timbul di sepanjang rantai. Insiden kecil yang terjadi pada satu aktor rantai pasok dapat berubah menjadi konsekuensi yang merugikan untuk aktor lain dalam rantai pasok. Karena kerentanan rantai pasok mengalami berbagai risiko internal dan eksternal, diperlukan sebuah mekanisme untuk mengidentifikasi dan mengukur bobot risiko rantai pasok agar dapat mempersiapkan segala situasi yang buruk sekalipun yang mungkin terjadi terutama ketika memperkenalkan produk baru ke pasar (Sarpong, 2013).

Berdasarkan hal tersebut, dirasa perlu untuk melakukan kajian risiko rantai pasok biodiesel dari minyak goreng bekas di Kota Padang. Kajian pengukuran bobot risiko ini diharapkan dapat menggerakkan pemerintah untuk lebih melirik potensi produksi bahan bakar alternatif biodiesel yang salah satunya berasal dari minyak goreng bekas.

\section{Metode Penelitian}

Metoda yang digunakan dalam pengolahan data dalam penelitian ini adalah fuzzy analytical hierarchy process (Fuzzy AHP). Fuzzy AHP merupakan teknik pembobotan risiko menggunakan pendapat para pakar. Banyak pakar yang digunakan adalah lima orang akademisi di bidang biodiesel. Penentuan pakar ini berdasarkan rekam jejak yang bersangkutan baik penelitian maupun publikasi.

Langkah-langkah yang dilakukan dalam metoda fuzzy AHP yaitu (Marimin et al, 2013 dan Anshori, 2012):

1. Penyusunan struktur hirarki Pembuatan hirarki bertujuan untuk menguraikan permasalahan menjadi bagian yang lebih kecil dan sederhana. Struktur hirarki terdiri dari beberapa tingkatan yaitu tujuan, faktor risiko dan indikator risiko.

2. Perbandingan berpasangan.

Perbandingan berpasangan dilakukan dengan memberikan penilaian tingkat kepentingan dua kriteria. Penentuan tingkat kepentingan tersebut menggunakan skala yang dapat dilihat pada Tabel 1.

3. Mengubah variabel linguistik dalam bentuk bilangan fuzzy

Data yang didapatkan dari kuisioner dalam bentuk variabel linguistik selanjutnya dikonversikan ke bilangan triangular fuzzy number (TFN). Konversi nilai TFN dapat dilihat pada Tabel 2.

4. Menghitung rata-rata geometris dari penilaian pakar

Hasil penilaian pakar yang telah dikonversikan ke bilangan TFN selanjutnya dihitung rata-rata geometrisnya berdasarkan nilai 
Tabel 1: Skala penilaian perbandingan berpasangan (Reddy \& Kousalya, 2015)

Variabel Linguistik AHP

Kedua elemen sama penting

Skala

Kedua elemen mendekati sama penting

Elemen yang satu sedikit lebih penting dari-

pada elemen yang lainnya

Elemen yang satu mendekati lebih penting 4

daripada elemen yang lainnya

Elemen yang satu lebih penting daripada 5

yang lainnya

Elemen yang satu mendekati sangat lebih 6

penting daripada yang lainnya

Satu elemen jelas lebih penting daripada elemen lainnya

Satu elemen mutlak lebih penting daripada 8

elemen lainnya

Satu elemen mutlak penting daripada elemen $\quad 9$

lainnya

Tabel 2: Konversi skala fuzzy (Anshori, 2012)

\begin{tabular}{|l|r|r|}
\hline Skala AHP & Skala Fuzzy & Invers Skala Fuzzy \\
\hline 1 & $1,1,3$ & $1 / 3,1 / 1,1 / 1$ \\
\hline 3 & $1,3,5$ & $1 / 5,1 / 3,1 / 1$ \\
\hline 5 & $3,5,7$ & $1 / 7,1 / 5,1 / 3$ \\
\hline 7 & $5,7,9$ & $1 / 9,1 / 7,1 / 5$ \\
\hline 9 & $7,9,9$ & $1 / 9,1 / 9,1 / 7$ \\
\hline 2 & $1,2,4$ & $1 / 4,1 / 2,1 / 1$ \\
\hline 4 & $2,4,6$ & $1 / 6,1 / 4,1 / 2$ \\
\hline 6 & $4,6,8$ & $1 / 8,1 / 6,1 / 4$ \\
\hline 8 & $6,8,9$ & $1 / 9,1 / 8,1 / 6$ \\
\hline
\end{tabular}

batas bawah (l), nilai tengah (m), dan nilai batas atas $(\mathrm{u})$. Rumus yang digunakan untuk menghitung rata-rata geometris adalah sebagai berikut:

$$
\begin{aligned}
l_{i} & =\sqrt[n]{l_{1} \times l_{2} \times \ldots \times l_{n}} \\
m_{i} & =\sqrt[n]{m_{1} \times m_{2} \times \ldots \times m_{n}} \\
u_{i} & =\sqrt[n]{u_{1} \times u_{2} \times \ldots \times u_{n}}
\end{aligned}
$$

Dimana:

$l_{i}=$ Nilai rata-rata geometri terkecil

$m_{i}=$ Nilai rata-rata geometri tengah

$u_{i}=$ Nilai rata-rata geometri terbesar

$n=$ Banyak pakar

\section{Defuzzifikasi}

Nilai rata-rata geometris yang didapatkan dari perhitungan diatas dilakukan defuzzifikasi untuk mengubah bilangan fuzzy menjadi nilai tunggal (crisp). Defuzzifikasi dihitung menggunakan nilai rata-rata geometris nilai batas bawah (l), nilai tengah $(\mathrm{m})$, dan nilai batas atas $(\mathrm{u})$.dengan rumus berikut

$$
D M_{i}=\frac{\left(u_{i}-l_{i}\right)+\left(m_{i}-l_{i}\right)}{3}+l_{i}
$$

Dimana:

$D M_{i}=$ Nilai defuzzifikasi kriteria i

6. Menghitung Bobot

Menentukan bobot alternatif untuk setiap faktor dan indikator.

$$
x_{i, j}^{\prime}=\frac{x_{i, j}}{\sum_{i=1}^{m} x_{i, j}}
$$

\section{Dimana:}

$x_{i, j}^{\prime}=$ Nilai perhitungan bobot kriteria i dibandingkan dengan kriteria j;

$x_{i, j}=$ Nilai evaluasi pada matriks perbandingan berpasangan untuk kriteria i dibandingkan dengan kriteria $j$;

$m=$ jumlah kriteria

Perhitungan bobot lokal dilakukan dengan menggunakan persamaan berikut:

$$
B_{i}=\frac{\sum_{i=1}^{m} x_{i, j}^{\prime}}{m}
$$

Dimana:

$B_{i}=$ Bobot lokal kriteria i;

\section{Uji Konsistensi}

Uji konsistensi dilakukan untuk mengetahui tingat konsistensi penentuan tingkat kepentingan oleh pengambil keputusan. Nilai rasio konsistensi harus 0,1. Jika lebih dari 0,1 berarti penilaiannya masih acak dan perlu diperbaiki. Tahapan dalam uji konsistensi yaitu (Imansuri, 2014):

(a) Perhitungan faktor penjumlahan bobot (Weight Sum Factor (WSF))

WSF diperoleh dengan mengalikan bobot kali hasil evaluasi yang telah dilakukan. Perhitungan WSF dilakukan menggunakan persamaan berikut:

$$
W S F_{i}=\sum_{j=1}^{m}\left(x_{i, j} \times B_{j}\right)
$$

Dimana: 
$W S F_{i}=$ Faktor penjumlah bobot

$B_{j} \quad=\quad$ Bobot lokal kriteria j, dimana $B_{i}=B_{j}$ jika i $=\mathrm{j}$

$x_{i, j} \quad=\quad$ Nilai hasil evaluasi pada matriks perbandingan berpasangan untuk kriteria i dibandingkan dengan kriteria $j$

(b) Perhitungan faktor konsistensi (Consistency Factor (CF))

$\mathrm{CF}$ diperoleh dengan pembagian faktor penjumlahan bobot kriteria i dengan bobot kriteria i. Perhitungan faktor konsistensi menggunakan persamaan berikut:

$$
C F_{i}=\frac{W S F_{i}}{B i}
$$

dimana:

$C F_{i}=$ Faktor konsistensi kriteria i

$W S F_{i}=$ Faktor penjumlah bobot kriteria i

$B_{i}=$ Bobot lokal kriteria i, dimana $B_{i}=B_{j}$ jika i=j

(c) Perhitungan indeks konsitensi (Consistency Index (CI))

CI diperoleh dengan menggunakan persamaan berikut:

$$
C I=\frac{\overline{C F}-m}{m-1}
$$

dimana:

$C I=$ Indeks konsistensi evaluasi kriteria;

$\overline{C F}=$ Rata-rata faktor konsistensi evaluasi kriteria

(d) Penentuan indeks rasio (Ratio Index (RI))

Nilai indeks rasio tergantung jumlah kriteria yang digunakan.

(e) Perhitungan rasio konsistensi (Consistency Ratio (CR))

Rasio konsistensi diperoleh dari hasil pembagian indeks konsistensi dengan indeks rasio. Persamaan yang bisa digunakan adalah sebagai berikut:

$$
C R=\frac{C I}{R I}
$$

dimana:

$\mathrm{CR}=$ Rasio konsistensi

$\mathrm{CI}=$ Indeks konsistensi

$\mathrm{RI}=$ Indeks rasio

(f) Menghitung bobot global (global weight)

Nilai bobot global (global weight) didapatkan dengan membagi setiap nilai bobot kriteria dengan nilai penjumlahan bobot kriteria keseluruhan, sehingga didapatkan urutan rangking dari terkecil hingga terbesar.

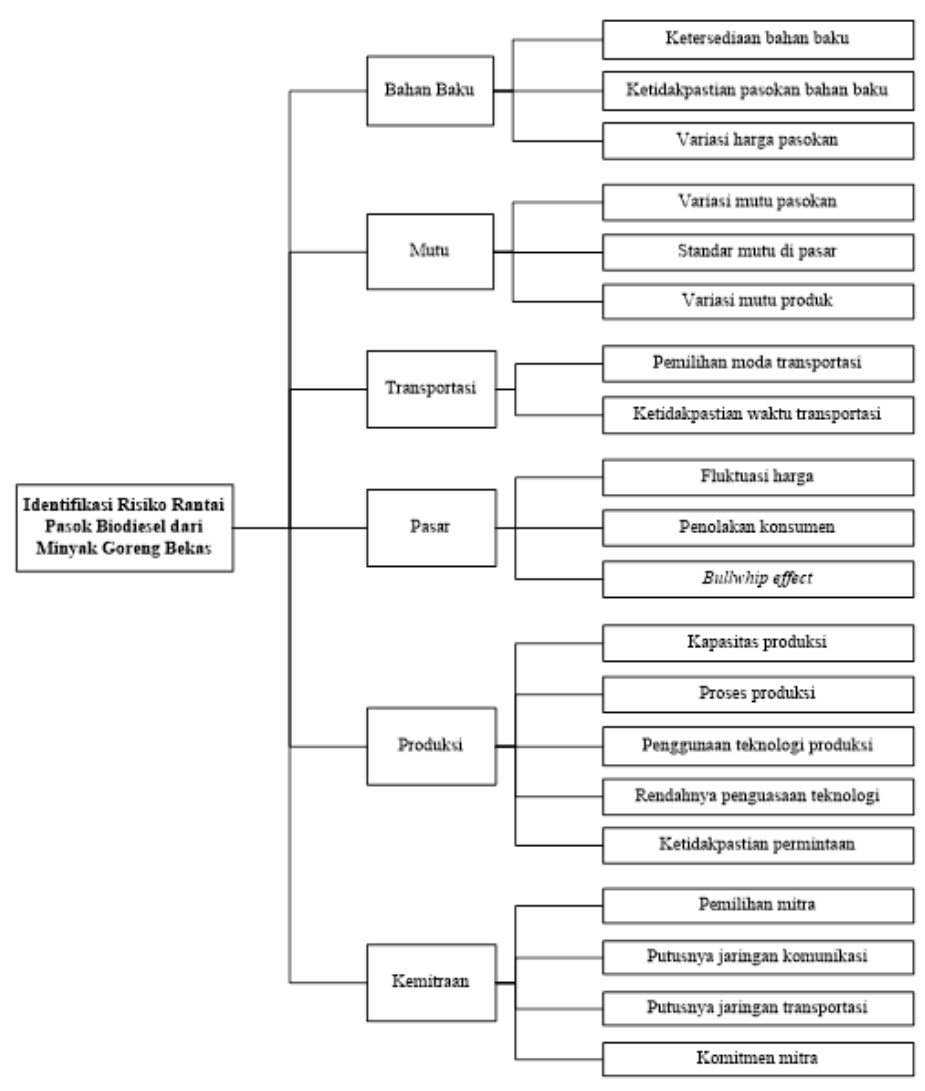

Gambar 2: Struktur hirarki risiko rantai pasok biodiesel dari minyak goreng bekas di Kota Padang

\section{Hasil dan Pembahasan}

\subsection{Penentuan Risiko}

Penentuan risiko dilakukan dengan studi literatur dan kuisioner penilaian pakar. Studi literatur dilakukan dengan mengumpulkan daftar sumber dan indikator risiko rantai pasok biodiesel dari minyak goreng bekas. Tabel 4 
adalah sumber-sumber risiko sedangkan Tabel 5 adalah indikator-indikator risiko.

Selanjutnya, sumber-sumber dan indikatorindikator risiko ini disusun dalam bentuk struktur hirarki. Struktur hirarki dibuat berdasarkan sumber-sumber risiko dan indikator-indikator risiko rantai pasok biodiesel dari minyak goreng bekas di Kota Padang yang telah diverifikasi oleh pakar. Hasil penilaian pakar terhadap sumber-sumber risiko dan indikator-indikator risiko diperoleh satu risiko yang tidak relevan yaitu risiko teknologi dan ada dua indikator yang tidak disetujui yaitu ketersediaan teknologi pengolahan yang terdapat pada risiko teknologi dan produk pesaing pada risiko pasar. Berdasarkan hasil diskusi dengan pakar disarankan untuk menambahkan satu faktor risiko lagi yaitu risiko mutu. Hal tersebut dikarenakan pakar menilai bahwa risiko mutu sangat dipertimbangkan dalam kegiatan rantai pasok. Indikator pada risiko mutu diambil dari beberapa indikator yang berhubungan dengan mutu yaitu variasi mutu pasokan, standar mutu di pasar, dan variasi mutu produk. Indikator yang disetujui pada risiko teknologi yaitu rendahnya penguasaan teknologi digabungkan dengan risiko produksi karena indikator tersebut lebih berkaitan dengan produksi. Struktur hirarki identifikasi risiko rantai pasok biodiesel dari minyak goreng bekas di Kota Padang dapat dilihat pada Gambar 2.

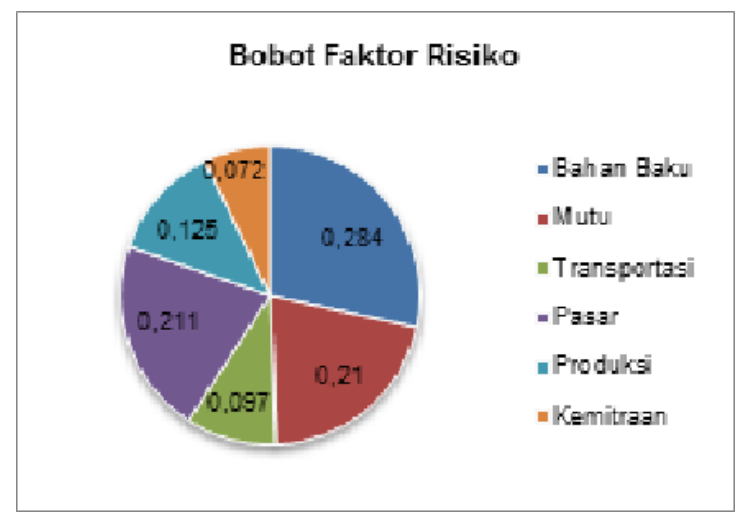

Gambar 3: Struktur Hirarki Risiko Rantai Pasok Biodiesel dari Minyak Goreng Bekas di Kota Padang

Sumber-sumber dan indikator-indikator risiko yang telah ditentukan diatas merupakan representasi dari para pemangku kepentingan. Rancangan sistem rantai pasok ini melibatkan pemangku kepentingan yaitu Pemerintah Kota Padang, Pertamina, industri minyak goreng dan perguruan tinggi. Peran dari setiap pemangku kepentingan saling melengkapi untuk mengatasi risiko.

\subsection{Prioritas Risiko}

Perbandingan berpasangan didapatkan dengan menggunakan kuisioner AHP yang dilakukan oleh empat orang akademisi. Kuisioner diisi berdasarkan nilai tingkat kepentingan AHP . Fuzzifikasi dilakukan dengan mengkonversi nilai perbandingan berpasangan ke nilai triangular fuzzy number (TFN). Fuzzifikasi dilakukan sesuai dengan ketentuan yang terdapat pada Tabel 2.

Langkah selanjutnya menghitung ratarata geometris yang dilakukan untuk menggabungkan penilaian yang dilakukan oleh empat orang pakar menjadi satu. Rata-rata geometris dihitung menggunakan nilai perbandingan berpasangan yang telah dikonversikan ke bilangan TFN. Selanjutnya masing-masing nilai lower (l), nilai medium ( $m)$, dan nilai upper (u) dihitung menggunakan rumus rata-rata geometris pada persamaan 1 .

Defuzzifikasi dilakukan untuk mengubah nilai hasil fuzzifikasi menjadi sebuah nilai tunggal. Perhitungan defuzzifikasi dilakukan dengan menggunakan nilai rata-rata geometris. Nilai llower ( $(\mathrm{l})$, nilai medium ( $m)$, dan nilai upper $(u)$ pada hasil rata-rata geometris diproses menggunakan persamaan 2 .

Tabel 3: Rekapitulasi hasil perbandingan berpasangan risiko

\begin{tabular}{|c|c|c|c|c|c|}
\hline \multirow{2}{*}{ Risiko (A) } & \multicolumn{7}{|c|}{ Pakar } & \multirow{2}{*}{ Risiko(B) } \\
\cline { 2 - 6 } & 1 & 2 & 3 & 4 & \\
\hline Bahan Baku & 3 & 3 & 3 & 3 & Mutu \\
\hline Bahan Baku & 2 & 4 & 2 & 3 & Transportasi \\
\hline Bahan Baku & 2 & $1 / 2$ & $1 / 2$ & 2 & Pasar \\
\hline Bahan Baku & 2 & 2 & 1 & 2 & Produksi \\
\hline Bahan Baku & 3 & 5 & 1 & 2 & Kemitraan \\
\hline \multicolumn{7}{|c|}{} \\
\hline Mutu & $1 / 2$ & 8 & 2 & 4 & Transportasi \\
\hline Mutu & 1 & 2 & 1 & 1 & Pasar \\
\hline Mutu & 3 & 1 & 1 & 1 & Produksi \\
\hline Mutu & 1 & 4 & 2 & 2 & Kemitraan \\
\hline \multicolumn{7}{|l|}{} \\
\hline Transportasi & 2 & $1 / 8$ & $1 / 3$ & $1 / 3$ & Pasar \\
\hline Transportasi & 2 & $1 / 7$ & 2 & $1 / 3$ & Produksi \\
\hline Transportasi & 2 & $1 / 3$ & 1 & $1 / 3$ & Kemitraan \\
\hline \multicolumn{7}{|l|}{} \\
\hline Pasar & 3 & 1 & 3 & 2 & Produksi \\
\hline Pasar & 2 & 4 & 2 & 1 & Kemitraan \\
\hline \multicolumn{7}{|l|}{} \\
\hline Produksi & 3 & 4 & 2 & 1 & Kemitraan \\
\hline
\end{tabular}

Perhitungan bobot dilakukan untuk mendapatkan bobot dari setiap risiko dan indikator risiko. Perhitungan bobot didapatkan dari nilai rata-rata normalisasi hasil matrik perbandin- 
gan berpasangan berdasarkan nilai hasil defuzzifikasi.

Langkah pertama dilakukan normalisasi untuk setiap matrik perbandingan berpasangan. Langkah kedua dilanjutkan dengan perhitungan bobot risiko. Berikut ini merupakan contoh perhitungan bobot risiko bahan baku.

Perhitungan konsistensi rasio dilakukan untuk menilai apakah penilaian setiap risiko dan indikator sudah konsisten atau belum. Jika nilai konsistensi rasio 0,1 maka kuisioner direvisi hingga didapatkan konsistensi rasio dengan nilai konsisten. Konsistensi rasio dihitung dengan mengalikan matrik hasil defuzzifikasi dengan nilai bobot yang diperoleh untuk mendapatkan nilai weight sum factor, dilanjutkan dengan menghitung konsistensi faktor, rata-rata konsistensi faktor, konsistensi indeks, dan terakhir baru didapatkan nilai konsistensi rasio. Berdasarkan hasil perhitungan konsistensi rasio didapatkan nilai konsistensi rasio yang konsisten untuk penilaian faktor risiko yaitu dengan nilai 0,051 . Sedangkan untuk indikator risiko bahan baku didapatkan nilai konsistensi rasio 0,003 , indikator mutu dengan nilai 0,006 , indikator transportasi dengan nilai 0,0 , indikator pasar dengan nilai 0,001 , indikator produksi dengan nilai 0,039 , dan indikator kemitraan dengan nilai 0,019 . Nilai konsistensi rasio yang didapatkan untuk semua indikator 0,1 sehingga tidak diperlukan lagi dilakukan revisi.

Nilai bobot global (global weight) didapatkan dengan mengalikan nilai bobot risiko dengan nilai bobot indikator, sehingga didapatkan urutan rangking risiko dan indikator dari terbesar hingga terkecil. Hasil perhitungan bobot global dapat dilihat pada Tabel 7 .

Jaringan rantai pasok yang dijadikan acuan dalam penelitian ini yaitu rancangan jaringan rantai pasok biodiesel dari minyak goreng bekas yang dirancang oleh Hadiguna dan Putra (2015). Penentuan aktor rantai pasok yang terlibat dengan hasil pembobotan risiko dilakukan berdasarkan penilaian pakar. Berdasarkan hasil pembobotan risiko didapatkan faktor risiko dengan bobot terbesar yaitu risiko bahan baku. Risiko yang ditimbulkan akibat risiko bahan baku ini akan berdampak pada kegiatan agen pengumpul yang mungkin akan merasakan dampak risiko jika risiko yang tidak diinginkan tersebut terjadi. Minyak goreng bekas dikumpulkan oleh agen pengumpul sehingga jika bahan baku tidak tersedia kegiatan pengumpulan tidak berjalan. Kondisi yang sama terjadi pada pihak produksi, dimana jika bahan baku tidak tersedia maka kegiatan produksi biodiesel tidak dapat dilaksanakan. Hasil perhitungan bobot risiko dapat dilihat pada Gambar 3.

Risiko pasar yang memiliki bobot tertinggi kedua pada jaringan rantai pasok akan berdampak pada aktor penjualan yaitu distributor dan retailer. Penjualan memiliki kewajiban memasarkan biodiesel baik untuk dijual kembali maupun digunakan langsung oleh konsumen. Namun untuk indikator risiko bullwhip effect akan berdampak pada semua aktor rantai pasok mulai dari pemasok, pengumpul, produksi, distribusi, dan penjualan karena distorsi informasi dapat menyebabkan terjadinya penumpukan minyak goreng bekas ataupun biodiesel disetiap aktor rantai pasok. Hal yang dapat terjadi seperti penumpukan minyak goreng bekas pada pengumpul, pihak produksi yang memproduksi melebihi permintaan, dan penumpukan biodiesel pada distribusi dan penjualan.

Risiko mutu dengan bobot terbesar ketiga, dampaknya akan dirasakan pihak produksi. Mutu pasokan yang bervariasi akan menyebabkan proses yang dilakukan pada produksi juga semakin panjang. Karena sebelum diproduksi menjadi biodiesel minyak goreng bekas harus melalui proses penjernihan terlebih dahulu. Semakin sering minyak goreng digunakan sebelumnya maka proses penjernihan juga akan membutuhkan proses yang panjang. Indikator risiko variasi mutu produk juga akan dirasakan oleh pihak produksi karena jika biodiesel diproduksi dengan kualitas yang tidak sesuai standar maka biodiesel tidak akan bisa dipasarkan dan menimbulkan kerugian pada pihak produksi.

Risiko produksi yang memiliki bobot terbesar keempat sudah pasti akan dirasakan oleh pihak produksi biodiesel. Produksi minyak goreng bekas menjadi biodiesel memperhatikan kapasitas produksi, permintaan konsumen, perencanaan produksi, dan penggunaan teknologi yang risikonya akan dirasakan sendiri oleh pihak produksi tersebut. Sedangkan jika produksi tidak berjalan maka aktor distribusi dan penjualan juga akan merasakan dampaknya karena tidak tersedianya produk biodiesel yang akan dijual dipasar.

Risiko yang memiliki bobot terbesar kelima dalam rantai pasok biodiesel dari minyak goreng bekas adalah risiko transportasi. Transportasi memiliki peranan yang cukup besar dalam rantai pasok karena membantu dalam segala proses perpindahan material. Dampak risiko yang ditimbulkan oleh transportasi akan dirasakan oleh pihak produksi dan distributor. Proses produksi biodiesel dapat dilaksanakan 
jika bahan baku berupa minyak goreng bekas sudah tersedia di pabrik, jika kedatangan bahan baku terlambat maka kegiatan produksi biodiesel juga akan terlambat. Pihak distribusi juga akan merasakan dampak yang ditimbulkan akibat risiko transportasi ini, karena pemasaran produk dari pabrik hingga sampai ke konsumen melibatkan moda transportasi yang jika terjadi masalah akan menyebabkan biodiesel tidak sampai ke tangan konsumen.

Risiko kemitraan merupakan faktor risiko yang memiliki bobot terkecil diantara keenam faktor risiko. Walaupun memiliki bobot terkecil namun jika risiko kemitraan ini tidak diperhatikan dampaknya akan dirasakan oleh semua aktor rantai pasok. Mulai dari pemasok, pengumpul, produksi, distributor, retailer, dan konsumen akan merasakan dampak yang terjadi akibat risiko kemitraan ini. Sebagai contoh jika pada kondisi tertentu pemasok tidak mau menjual minyak goreng bekasnya kepada pengumpul maka kegiatan produksi, distribusi, dan penjualan juga tidak dapat dilaksanakan, sehingga biodiesel tidak sampai ke tangan konsumen.

Hasil penentuan prioritas risiko merupakan petunjuk awal bagi pemerintah Kota Padang untuk merumuskan kebijakan. Aspek bahan baku membutuhkan kebijakan model pengumpulan minyak goring bekas dari masyarakat baik rumah tangga ataupun restoran. Pasar membutuhkan komitmen dari pemerintah untuk bersedia membeli biodiesel. Mutu biodiesel telah dirumuskan oleh pemerintah dan perlu dirujuk oleh pengolah biodiesel. Produksi adalah aspek bagi investor tetapi perlu difasilitasi oleh pemerintah dalam hal iklim usaha dan kemudahan investasi. Transportasi telah tersedia tetapi perlu dukungan infrastruktur jalan yang memadai untuk kelancaran pendistribusian. Kemitraan berkaitan dengan kerjasama komersial sehingga peran pemerintah adalah menjamin terjaganya iklim usaha dengan baik.

\section{Kesimpulan}

Risiko rantai pasok biodiesel dari minyak goreng bekas di Kota Padang teridentifikasi sebanyak enam risiko yaitu bahan baku, mutu, transportasi, pasar, produksi, dan kemitraan. Indikator yang teridentifikasi sebanyak 20 indikator, 3 indikator bahan baku yaitu ketersediaan bahan baku, ketidakpastian pasokan bahan baku, variasi harga pasokan, 3 indikator mutu yaitu variasi mutu pasokan, standar mutu di pasar, variasi mutu produk, 2 indika- tor transportasi yaitu pemilihan moda transportasi, ketidakpastian waktu transportasi, 3 indikator pasar yaitu fluktuasi harga, penolakan konsumen, bullwhip effect, 5 indikator produksi yaitu kapasitas produksi, proses produksi, penggunaan teknologi produksi, rendahnya penguasaan teknologi, ketidakpastian permintaan, dan 4 indikator kemitraan yaitu pemilihan mitra, putusnya jaringan komunikasi, putusnya jaringan transportasi, dan komitmen mitra.

Bobot risiko yang diperoleh dari nilai terbesar hingga terkecil yaitu risiko bahan baku, pasar, mutu, produksi, transportasi, dan kemitraan. Sedangkan urutan bobot indikator secara keseluruhan yaitu ketidakpastian pasokan bahan baku, ketersediaan bahan baku, penolakan konsumen, variasi mutu pasokan, bullwhip effect, standar mutu di pasar, pemilihan moda transportasi, variasi harga pasokan, variasi mutu produk, fluktuasi harga, ketidakpastian permintaan, komitmen mitra, kapasitas produksi, proses produksi, rendahnya penguasaan teknologi, penggunaan teknologi produksi, putusnya jaringan transportasi, pemilihan mitra dan putusnya jaringan komunikasi. Indikator ketidakpastian pasokan bahan baku memiliki bobot terbesar dikarenakan volume ketersediaan pasokan bahan baku di Kota Padang tidak dapat dipastikan karena jumlah pasokan sepenuhnya tergantung kepada penghasil minyak goreng bekas. Pemerintah dapat memberikan sosialisasi kepada masyarakat Kota Padang tentang bahaya mengkonsumsi minyak goreng bekas dan manfaat pengolahan limbah minyak goreng bekas menjadi biodiesel agar masyarakat Kota Padang tergerak untuk menjual minyak goreng bekasnya sehingga ketersediaan pasokan bahan baku dapat terjamin.

\section{Ucapan Terima Kasih}

Artikel ini merupakan bagian dari kegiatan Penprinas MP3EI yang didanai oleh Kemenristekdikti dengan Nomor Kontrak: 030/SP2H/PL/DIT.LITABMAS/II/2015 tanggal 5 Februari 2015 


\section{Daftar Pustaka}

Anshori, Y. (2012). Pendekatan Triangular Fuzzy Number dalam Metode Analytic Hierarchy Process. Jurnal Ilmiah Foristek 2(1), 126-135.

Djamudin (2013). Manajemen Resiko Pengembangan Agroindustri Biodiesel Minyak Jarak Pagar. Jurnal Manajemen. 4(4), 79-88.

Geraldin, L.H, Pujawan, I.N, dan Dewi, D.S. (2007). Manajemen Risiko dan Aksi Mitigasi untuk Menciptakan Rantai Pasok yang Robust. Jurnal Teknologi dan Rekayasa Teknik Sipil TORSI. 53-64.

Hadiguna, R.A dan Putra, D. (2015).Dinamika Jaringan Rantai Pasok Biodiesel dari Minyak Goreng Bekas (Analisis, Permodelan dan Kebijakan). Padang: Andalas University Press.

Hidayat, S. Marimin. Suryani, A. Sukardi, dan Yani, M. (2012). Model Identifikasi Risiko dan Strategi Peningkatan Nilai Tambah pada Rantai Pasok Kelapa Sawit.Jurnal Teknik Industri. 14(2). 89-96.

Imansuri, F. (2014). Perumusan Key Performanc Indicator (KPI) Untuk Penilaian Kampus Berkelanjutan (Sustainable Campus) Di Universitas Andalas. Tugas Akhir. Universitas Andalas.

Jaya, R. Machfud, Raharja, S, dan Marimin. (2014). Anilisis dan Mitigasi Risiko Rantai Pasok Kopi Gayo Berkelanjutan dengan Pendekatan Fuzzy. Journal Teknologi Industri Pertanian. 24(1). 61-71.

Jenlina. (2013). Desain Risk Management untuk Rantai Pasok PT. X.Jurnal Ilmiah Mahasiswa Universitas Surabaya. 2(2). 1-19.

Lu, Y. (2015). Supply Chain Risk Assessment Based on AHP and Fuzzy Comprehensive Assessment Mode: A Case Study of the Chemical Supply Chain.International Journal of $u$ and e Service, Science, and Technology. 8(2). 227-234.

Mangla, S.C, Kumar, P, dan Barua, M.K. (2015). Risk Analysis in Green Supply Chain Using Fuzzy AHP Approach: A Case Study. Conservation and Recycling. 1-16.

Marimin et al. (2013). Teknik dan Analisis Pengambilan Keputusan fuzzy dalam Manajemen Rantai Pasok. Bogor : IPB Press.

Reddy, G.M dan Kousalya, P. (2015). Trapezoidal Fuzzy Numbers in Extent Analysis Method in Fuzzy AHP. International Journal of Conceptions on Computing and Information Technology. 3(1). 69-71.
Sarpong, K.O, Alexander, O.F, dan Anin, E.K (2013). An Assessment of Supply Chain Risks in the Cocoa Industry in the Ashanti Region, Ghana. International Journal of Humanities and Social Science. 3(19). 191-201

Septiani, W dan Djatna, T. (2015). Rancangan Model Performansi Risiko Rantai Pasok Agroindustri Susu dengan Menggunakan Pendekatan Logika Fuzzy. Agritech. 35(1). 8897.

Suharjito, Marimin, Machfud, dan Sukardi. (2010). Identifikasi dan Evaluasi Risiko Manajemen Rantai Pasok Komoditas Jagung dengan Pendekatan Logika Fuzzy. Jurnal Manajemen dan Organisasi. 2(1). 118-134.

Wijaya, K (2011). Biodiesel Dari Minyak Goreng Bekas. Diakses dari http://www.pse.ugm.ac.id/. 
Tabel 4: Sumber-sumber risiko

\begin{tabular}{|c|c|c|c|}
\hline No & Risiko & Deskripsi & Sumber \\
\hline 1 & Bahan Baku & $\begin{array}{l}\text { Bahan baku pembuatan biodiesel dari minyak goreng bekas } \\
\text { dipengaruhi oleh produsen penghasil minyak goreng bekas yang } \\
\text { dihadapkan pada berbagai ketidakpastian dari segi jumlah, mutu, } \\
\text { dan harga yang ditawarkan }\end{array}$ & $\begin{array}{l}\text { Septiani dan Djatna (2015), Jaya, } \\
\text { et al (2014), Hidayat, et al (2012) } \\
\text { \& Suharjito, et al (2010) }\end{array}$ \\
\hline 2 & Teknologi & $\begin{array}{l}\text { Teknologi yang digunakan untuk pengolahan biodiesel dari } \\
\text { minyak goreng bekas dihadapkan pada tantangan pemenuhan } \\
\text { standar mutu dan skala ekonomis }\end{array}$ & $\begin{array}{l}\text { Hidayat, et al (2012) \& Suharjito, } \\
\text { et al (2010) }\end{array}$ \\
\hline 3 & Transportasi & $\begin{array}{l}\text { Transportasi mempengaruhi setiap kegiatan yang berlangsung } \\
\text { disepanjang rantai pasok mulai dari pergerakan bahan baku } \\
\text { hingga produk sampai ke tangan konsumen }\end{array}$ & $\begin{array}{l}\text { Lu (2015), Septiani dan Djatna } \\
\text { (2015), Jenlina (2013), Hidayat, et } \\
\text { al (2012) \& Suharjito, et al (2010) }\end{array}$ \\
\hline 4 & Pasar & $\begin{array}{l}\text { Produk biodiesel belum dikenal secara luas oleh masyarakat } \\
\text { karena pasar bahan bakar masih dikelola oleh Pertamina }\end{array}$ & $\begin{array}{l}\text { Hidayat, et al (2012) \& Suharjito, } \\
\text { et al (2010) }\end{array}$ \\
\hline 5 & Produksi & $\begin{array}{l}\text { Volume produksi biodiesel dari minyak goreng bekas membu- } \\
\text { tuhkan perencanaan yang baik karena belum pernah diproduksi } \\
\text { di Kota Padang untuk tujuan komersial }\end{array}$ & $\begin{array}{l}\text { Lu (2015), Hidayat, et al (2012) \& } \\
\text { Suharjito, et al (2010) }\end{array}$ \\
\hline 6 & Kemitraan & $\begin{array}{l}\text { Kemitraan dimaksudkan untuk mendukung kelancaran pasokan } \\
\text { dalam rantai pasok untuk keberlangsungan produksi }\end{array}$ & $\begin{array}{l}\text { Lu (2015), Hidayat et al (2012) \& } \\
\text { Suharjito, et al (2010) }\end{array}$ \\
\hline
\end{tabular}

\section{Tabel 5: Indikator-Indikator Risiko}

\begin{tabular}{|c|c|c|c|}
\hline No & Indikator & Deskripsi & Sumber \\
\hline \multicolumn{4}{|c|}{ Risiko Bahan Baku } \\
\hline 1 & $\begin{array}{l}\text { Ketersediaan } \\
\text { baku }\end{array}$ & $\begin{array}{l}\text { Bahan baku berupa minyak goreng bekas harus } \\
\text { dikumpulkan terlebih dahulu dari berbagai sumber } \\
\text { penghasil minyak goreng bekas sehingga dihadapkan } \\
\text { pada ketidakpastian volume ketersediaan }\end{array}$ & $\begin{array}{l}\text { Djamudin }(2013) \quad \& \\
\text { Suharjito, et al (2010) }\end{array}$ \\
\hline 2 & $\begin{array}{l}\text { Ketidakpastian pasokan } \\
\text { bahan baku }\end{array}$ & $\begin{array}{l}\text { Minyak goreng bekas yang ditawarkan oleh pemasok } \\
\text { memiliki jumlah yang tidak pasti yang disebabkan ke- } \\
\text { mauan masyarakat untuk menjual }\end{array}$ & Suharjito, et al (2010) \\
\hline 3 & Variasi mutu pasokan & $\begin{array}{l}\text { Mutu minyak goreng bekas yang ditawarkan setiap pe- } \\
\text { masok berbeda-beda tergantung bagaimana pemasok } \\
\text { tersebut menggunakan minyak goreng sebelumnya }\end{array}$ & Suharjito, et al (2010) \\
\hline 4 & Variasi harga pasokan & $\begin{array}{l}\text { Harga yang ditawarkan pemasok berbeda-beda tergan- } \\
\text { tung mutu minyak goreng bekas yang ditawarkan }\end{array}$ & $\begin{array}{l}\text { Djamudin (2013) \& } \\
\text { Suharjito, et al (2010) }\end{array}$ \\
\hline \multicolumn{4}{|c|}{ Risiko Teknologi } \\
\hline 5 & $\begin{array}{l}\text { Ketersediaan teknologi } \\
\text { untuk pengolahan }\end{array}$ & $\begin{array}{l}\text { ketersediaan teknologi pengolahan biodiesel dari minyak } \\
\text { goreng bekas masih terbatas }\end{array}$ & Suharjito, et al (2010) \\
\hline 6 & $\begin{array}{l}\text { Rendahnya penguasaan } \\
\text { teknologi }\end{array}$ & $\begin{array}{l}\text { Penguasaan teknologi pengolahan biodiesel masih ter- } \\
\text { batas oleh kalangan tertentu }\end{array}$ & Suharjito, et al (2010) \\
\hline \multicolumn{4}{|c|}{ Risiko Tranportasi } \\
\hline 7 & $\begin{array}{l}\text { Pemilihan moda trans- } \\
\text { portasi }\end{array}$ & $\begin{array}{l}\text { Penggunaan moda dan tipe transportasi yang tidak tepat } \\
\text { dapat mengakibatkan masalah di sepanjang rantai pasok }\end{array}$ & $\begin{array}{l}\text { Lu (2015), Suharjito, et al } \\
(2010)\end{array}$ \\
\hline 8 & $\begin{array}{l}\text { Ketidakpastian waktu } \\
\text { transportasi }\end{array}$ & $\begin{array}{l}\text { Waktu yang dibutuhkan dalam pengangkutan dapat } \\
\text { mempengaruhi setiap kegiatan di sepanjang rantai pasok }\end{array}$ & $\begin{array}{l}\text { Suharjito, et al (2010), } \\
\text { Geraldin (2007) }\end{array}$ \\
\hline \multicolumn{4}{|c|}{ Risiko Pasar } \\
\hline 9 & Fluktuasi harga & $\begin{array}{l}\text { Harga biodiesel dipasaran dapat naik turun karena tidak } \\
\text { adanya ketetapan harga }\end{array}$ & Suharjito, et al (2010) \\
\hline 10 & Penolakan konsumen & $\begin{array}{l}\text { Biodiesel belum terlalu dikenal oleh masyarakat sehingga } \\
\text { berkemungkinan kurang diminati masyarakat }\end{array}$ & Suharjito, et al (2010) \\
\hline 11 & Standar mutu di pasar & $\begin{array}{l}\text { Biodiesel harus memiliki mutu yang sesuai standar yang } \\
\text { ditetapkan pemerintah untuk dapat bersaing di pasar }\end{array}$ & Suharjito, et al (2010) \\
\hline 12 & Produk pesaing & Bahan bakar fosil masih mendominasi pasar & Suharjito, et al (2010) \\
\hline 13 & Bullwhip Effect & Distorsi informasi terkait permintaan biodiesel & $\begin{array}{l}\text { Mangla, Kumar \& Barua } \\
\text { (2015) }\end{array}$ \\
\hline \multicolumn{4}{|c|}{ Risiko Produksi } \\
\hline 14 & Kapasitas produksi & Kapasitas produksi harus memenuhi skala ekoomis & $\begin{array}{l}\text { Lu (2015), Septiani dan } \\
\text { Djatna (2015), Suharjito, } \\
\text { et al (2010) }\end{array}$ \\
\hline 15 & Proses produksi & $\begin{array}{l}\text { Proses produksi dilakukan sesuai standar yang ditetap- } \\
\text { kan untuk memenuhi mutu biodiesel }\end{array}$ & Suharjito, et al (2010) \\
\hline 16 & $\begin{array}{l}\text { Penggunaan teknologi } \\
\text { produksi }\end{array}$ & $\begin{array}{l}\text { Penggunaan teknologi produksi dapat mempengaruhi bi- } \\
\text { aya produksi }\end{array}$ & Suharjito, et al (2010) \\
\hline 17 & $\begin{array}{l}\text { Ketidakpastian per- } \\
\text { mintaan }\end{array}$ & $\begin{array}{l}\text { Permintaan yang tidak pasti mengharuskan pihak pro- } \\
\text { duksi untuk memproduksi biodiesel dalam jumlah yang } \\
\text { tepat }\end{array}$ & $\begin{array}{l}\text { Lu (2015), Septiani dan } \\
\text { Djatna (2015), Jaya et al } \\
\text { (2014), Suharjito, et al } \\
(2010)\end{array}$ \\
\hline 18 & Variasi mutu produk & $\begin{array}{l}\text { Adanya gangguan teknis dapat memicu variasi mutu } \\
\text { biodiesel }\end{array}$ & Suharjito, et al (2010) \\
\hline
\end{tabular}


Tabel 5: Indikator-Indikator Risiko (lanjutan)

\begin{tabular}{|c|c|c|c|}
\hline No & Indikator & Deskripsi & Sumber \\
\hline \multicolumn{4}{|c|}{ Risiko Kemitraan } \\
\hline 19 & Pemilihan mitra & $\begin{array}{l}\text { Pemilihan mitra yang buruk dapat mengakibatkan selu- } \\
\text { ruh jaringan rantai pasok terganggu }\end{array}$ & $\begin{array}{l}\text { Jenlina (2013), Suharjito, } \\
\text { et al (2010) }\end{array}$ \\
\hline 20 & $\begin{array}{l}\text { Putusnya jaringan ko- } \\
\text { munikasi }\end{array}$ & $\begin{array}{l}\text { Putusnya jaringan komunikasi mengakibatkan terputus- } \\
\text { nya informasi sehingga mengganggu kelancaran kegiatan } \\
\text { di rantai pasok }\end{array}$ & Suharjito, et al (2010) \\
\hline 21 & $\begin{array}{l}\text { Putusnya jaringan trans- } \\
\text { portasi }\end{array}$ & $\begin{array}{l}\text { Putusnya jaringan transportasi dapat mengakibatkan } \\
\text { kegiatan rantai pasok terhenti }\end{array}$ & Suharjito, et al (2010) \\
\hline 22 & Komitmen mitra & $\begin{array}{l}\text { Komitmen mitra diperlukan untuk menjaga keberlang- } \\
\text { sungan kegiatan di sepanjang rantai pasok }\end{array}$ & $\begin{array}{l}\text { Lu (2015), Suharjito, et al } \\
\text { (2010) }\end{array}$ \\
\hline
\end{tabular}

Tabel 6: Rekapitulasi hasil perbandingan berpasangan indikator

\begin{tabular}{|c|c|c|c|c|c|}
\hline \multirow[t]{2}{*}{ Indikator (A) } & \multicolumn{4}{|c|}{ Pakar } & \multirow[t]{2}{*}{ Indikator(B) } \\
\hline & 1 & 2 & 3 & 4 & \\
\hline \multicolumn{6}{|c|}{ Risiko Bahan Baku } \\
\hline Ketersediaan bahan baku & 1 & 1 & $1 / 4$ & $1 / 4$ & Ketidakpastian pasokan bahan baku \\
\hline Ketersediaan bahan baku & 5 & 3 & $1 / 3$ & $1 / 4$ & Variasi harga pasokan \\
\hline Ketidakpastian pasokan bahan baku & 3 & 3 & 1 & 1 & Variasi harga pasokan \\
\hline \multicolumn{6}{|c|}{ Risiko Mutu } \\
\hline Variasi mutu pasokan & $1 / 2$ & 2 & 5 & 2 & Standar mutu di pasar \\
\hline Variasi mutu pasokan & 1 & 1 & 3 & $1 / 2$ & Variasi mutu produk \\
\hline Standar mutu di pasar & 3 & 1 & $1 / 3$ & $1 / 3$ & Variasi mutu produk \\
\hline \multicolumn{6}{|c|}{ Risiko Transportasi } \\
\hline Pemilihan moda transportasi & $1 / 3$ & 2 & 1 & 1 & Ketidakpastian waktu transportasi \\
\hline \multicolumn{6}{|c|}{ Risiko Pasar } \\
\hline Fluktuasi Harga & $1 / 3$ & $1 / 3$ & $1 / 5$ & $1 / 4$ & Penolakan konsumen \\
\hline Fluktuasi Harga & $1 / 2$ & 2 & $1 / 4$ & $1 / 3$ & Bullwhip effect \\
\hline Penolakan konsumen & 3 & 3 & $1 / 2$ & 3 & Bullubin effect \\
\hline \multicolumn{6}{|c|}{ Risiko Produksi } \\
\hline Kapasitas produksi & 2 & 4 & $1 / 2$ & $1 / 3$ & Proses produksi \\
\hline Kapasitas produksi & 1 & 2 & 1 & $1 / 3$ & Penggunaan teknologi produksi \\
\hline Kapasitas produksi & $1 / 2$ & $1 / 2$ & 2 & $1 / 3$ & Rendahnya penguasaan teknologi \\
\hline Kapasitas produksi & $1 / 3$ & 1 & $1 / 4$ & $1 / 3$ & Ketidakpastian permintaan \\
\hline Proses produksi & 2 & 1 & 3 & $1 / 3$ & Penggunaan teknologi produksi \\
\hline Proses produksi & $1 / 3$ & $1 / 2$ & 3 & $1 / 3$ & Rendahnya penguasaan teknologi \\
\hline Proses produksi & $1 / 3$ & $1 / 2$ & $1 / 2$ & $1 / 3$ & Ketidakpastian permintaan \\
\hline Penggunaan teknologi produksi & $1 / 3$ & 1 & 2 & $1 / 3$ & Rendahnya penguasaan teknologi \\
\hline Penggunaan teknologi produksi & $1 / 3$ & $1 / 2$ & $1 / 2$ & $1 / 3$ & Ketidakpastian permintaan \\
\hline Rendahnya penguasaan teknologi & $1 / 3$ & 2 & $1 / 4$ & 1 & Ketidakpastian permintaan \\
\hline \multicolumn{6}{|c|}{ Risiko Kemitraan } \\
\hline Pemilihan mitra & 1 & 2 & $1 / 2$ & 1 & Putusnya jaringan komunikasi \\
\hline Pemilihan mitra & $1 / 3$ & 2 & $1 / 2$ & 2 & Putusnya jaringan transportasi \\
\hline Pemilihan mitra & $1 / 3$ & $1 / 3$ & $1 / 5$ & $1 / 2$ & Komitmen mitra \\
\hline Putusnya jaringan komunikasi & $1 / 5$ & 3 & 1 & 3 & Putusnya jaringan transportasi \\
\hline Putusnya jaringan komunikasi & $1 / 3$ & $1 / 3$ & $1 / 5$ & $1 / 3$ & Komitmen mitra \\
\hline Putusnya jaringan transportasi & 3 & $1 / 3$ & $1 / 5$ & $1 / 2$ & Komitmen mitra \\
\hline
\end{tabular}


Tabel 7: Perhitungan Bobot Global

\begin{tabular}{|c|c|c|c|c|c|c|c|}
\hline Risiko & Bobot & Ranking & Indikator & Bobot & $\begin{array}{l}\text { Ranking } \\
\text { Lokal }\end{array}$ & Bobot Global & Ranking Global \\
\hline \multirow[t]{2}{*}{ Bahan Baku } & 0,284 & 1 & Ketersediaan bahan baku & 0,383 & 2 & 0,109 & 2 \\
\hline & & & Ketidakpastian pasokan bahan baku & 0,430 & 1 & 0,122 & 1 \\
\hline Mutu & 0,210 & 3 & Variasi mutu pasokan & 0,491 & 1 & 0,103 & 4 \\
\hline \multirow[t]{2}{*}{ Transportasi } & 0,097 & 5 & Pemilihan moda transportasi & 0,555 & 1 & 0,054 & 7 \\
\hline & & & Ketidakpastian waktu transportasi & 0,445 & 2 & 0,043 & 11 \\
\hline Pasar & 0,211 & 2 & Fluktuasi Harga & 0,204 & 3 & 0,043 & 10 \\
\hline \multirow[t]{5}{*}{ Produksi } & 0,125 & 4 & Kapasitas produksi & 0,218 & 2 & 0,027 & 14 \\
\hline & & & Proses produksi & 0,182 & 3 & 0,023 & 15 \\
\hline & & & Penggunaan teknologi produksi & 0,141 & 5 & 0,018 & 17 \\
\hline & & & Rendahnya penguasaan teknologi & 0,178 & 4 & 0,022 & 16 \\
\hline & & & Ketidakpastian permintaan & 0,281 & 1 & 0,035 & 12 \\
\hline \multirow[t]{4}{*}{ Kemitraan } & 0,072 & 6 & Pemilihan mitra & 0,191 & 3 & 0,014 & 19 \\
\hline & & & Putusnya jaringan komunikasi & 0,175 & 4 & 0,013 & 20 \\
\hline & & & Putusnya jaringan transportasi & 0,221 & 2 & 0,016 & 18 \\
\hline & & & Komitmen mitra & 0,413 & 1 & 0,030 & 13 \\
\hline
\end{tabular}

